\title{
Controle de convolvuláceas infestantes na cultura da cana-de-açúcar ${ }^{1}$
}

\section{Convolvulaceas weeds chemical control in sugar cane}

\author{
Felipe Ridolfo Lucio $^{2}$, Mariana Casari Parreira ${ }^{3}$, Fernanda Campos Mastrotti Pereira ${ }^{4}$, \\ Pedro Luis da Costa Aguiar Alves,
}

\begin{abstract}
Resumo - Dentre as plantas daninhas que podem causar sérios danos à cultura da cana-deaçúcar, algumas convolvuláceas merecem destaque. Além de competirem com a cana-de-açúcar, podem interferir nas práticas culturais, na colheita mecanizada, ou ainda reduzir sua qualidade e produtividade. Assim, este trabalho teve como objetivo verificar a eficiência de herbicidas aplicados em pré-emergência na cultura da cana-de-açúcar, na ausência ou presença de palha, para controle de seis espécies de cordas-de-viola. O delineamento experimental utilizado foi o inteiramente casualizado, em esquema fatorial 6x4x2 com três repetições, sendo seis espécies de Convolvulaceas (Ipomoea grandifolia (Dammer) O’Donell, I. hederifolia L., I. nil (L.) Roth, I. purpurea (L.) Roth, I. quamoclit L. e Merremia cissoides (Lam.) Hall. f) submetidas à aplicação dos herbicidas imazapic $\left(245 \mathrm{~g} \mathrm{ha}^{-1}\right)$, diuron + hexazinona $\left(1770+330 \mathrm{~g} \mathrm{ha}^{-1}\right)$ e clomazone + hexazinona $\left(720+180 \mathrm{~g} \mathrm{ha}^{-1}\right)$, além de uma testemunha sem aplicação, na ausência e presença de palha de cana-de-açúcar. As combinações dos herbicidas diuron + hexazinona e clomazone + hexazinona foram efetivas no controle das espécies Ipomoea grandifolia, Ipomoea hederifolia, Ipomoea nil, Ipomoea purpurea, Ipomoea quamoclit e Merremia cissoides, e o controle foi ligeiramente incrementado na presença de $12 \mathrm{t} \mathrm{ha}^{-1}$ de palha.
\end{abstract}

Palavras-Chave: Saccharum sp., herbicidas, pré-emergência, plantas daninhas.

\begin{abstract}
Some Convolvulaceas can cause serious damage to the sugarcane crop. In addition, can interfere on cultural practices, in mechanical harvesting, quality reducing and productivity. The aim of this estudy was verify effectiveness of some herbicides applied in pre-emergence of sugarcane culture in the absence or presence of straw, on control of six species of convolvuluses. The experimental was a completely randomized design, in a factorial with three replications, six species of Convolvulaceas (Ipomoea grandifolia, I. hederifolia, I. nil, I. purpurea, I. quamoclit and Merremia cissoides) submitted the application of herbicides imazapic ( $\left.245 \mathrm{~g} \mathrm{ha}^{-1}\right)$, diuron + hexazinona $\left(1770+330 \mathrm{~g} \mathrm{ha}^{-1}\right)$ and clomazone + hexazinona $\left(720+180 \mathrm{~g} \mathrm{ha}^{-1}\right)$, in the absence and presence of cane straw. The combinations diuron + hexazinone and clomazone + hexazinone were effective in control the species Ipomoea grandifolia, Ipomoea hederifolia, Ipomoea nil,

\footnotetext{
${ }^{1}$ Recebido para publicação em 16/08/2011 e aceito em 23/11/2011.

${ }^{2}$ Eng $^{\circ}$ Agr $^{\circ}$, Mestre em Agronomia, Faculdade de Ciências Agrarias e Veterinárias, UNESP Jaboticabal-SP.

${ }^{3}$ Eng $^{\mathbf{o}}$ Agro , Doutoranda em Agronomia, Laboratório de biologia e manejo de plantas daninhas (LAPDA), Faculdade de Ciências Agrarias e Veterinárias, UNESP Jaboticabal-SP.

${ }^{4}$ Eng $^{\mathrm{o}} \mathrm{Agr}^{\mathrm{o}}$, Mestranda em Agronomia, Laboratório de biologia e manejo de plantas daninhas (LAPDA), Faculdade de Ciências Agrarias e Veterinárias, UNESP Jaboticabal-SP.

${ }^{5}$ Prof $^{\circ}$ Dr $^{\circ}$. Laboratório de biologia e manejo de plantas daninhas (LAPDA), Faculdade de Ciências Agrarias e Veterinárias, UNESP Jaboticabal-SP.
} 
Ipomoea purpurea, Ipomoea quamoclit and Merremia cissoides, and the control was slightly increase in the presence of straw $\left(12 \mathrm{t} \mathrm{ha}^{-1}\right)$.

Key-words: Saccharum sp., herbicides, pre-emergence, weeds.

A cana-de-açúcar é uma das principais culturas agrícolas do país, e sua produção é crescente. A previsão do total de cana que será moída na safra 2010/11 é de 624,991 milhões de toneladas, com incremento de 3,40\% em relação à safra 2009/10, o que significa que haverá 20,477 milhões de toneladas a mais para moagem nesta safra (CONAB, 2011).

Como qualquer outra cultura, a cana-deaçúcar sofre interferências das plantas daninhas. A competição por água, luz, nutrientes e espaço pode levar a perdas significativas na produtividade, qualidade do produto colhido e longevidade do canavial (Kuva et al., 2003; Negrisoli et al., 2007).

As espécies de Ipomoea spp., pertencentes à família Convolvulaceae e são tradicionalmente conhecidas como campainhas ou cordas-de-viola. Entre muitas características dessa família, destaca-se a produção de cerca de 50 a 300 diásporos por planta. Dessas, somente um pequeno percentual germina prontamente; sendo que as demais germinam aleatoriamente ao longo do tempo (Kissmann \& Groth, 1999). Além disso, as sementes de algumas convolvuláceas tem sua germinação potencializada nos meses de verão, devido às melhores condições de calor e umidade (Azania et al., 2009b). Portanto, nesse período o monitoramento e o controle das plantas daninhas requer maior atenção.

Silva et al. (2009) verificaram que uma comunidade infestante com predominância de Ipomoea hederifolia tem potencial de redução de $34 \%$ no número final de colmos e $46 \%$ na produtividade da cana-de-açúcar, justificando plenamente a preocupação com seu controle.

A introdução da colheita mecanizada, principalmente na cultura da cana-de-açúcar induziu a manutenção dos resíduos vegetais (palhada) que oferece inúmeros benefícios, como redução na amplitude térmica e da evaporação da água na superfície, aumento do teor de matéria orgânica e da atividade de microorganismos, entre outros (Christoffoleti et al., 2007).

A palha também afeta drasticamente o estabelecimento das plantas daninhas, já que ocorre a formação de uma barreira física a ser transposta pela planta em germinação. O aumento da quantidade de microorganismos pode ainda contribuir para a decomposição das sementes, além dos possíveis efeitos alelopáticos que inibem a germinação (Correia \& Durigan, 2004). Essa série de modificações alterou a flora infestante e o posicionamento dos herbicidas utilizados (Kuva et al., 2008). Assim, plantas daninhas perenes, com grandes sementes (alta quantidade de reservas) e com reprodução vegetativa, como as cordas-deviola, tornaram-se problemáticas (Correia \& Durigan, 2004; Kuva et al., 2008).

Dependendo do grau de infestação, há a necessidade de mais de uma intervenção para o controle das plantas daninhas durante o ciclo da cultura, já que os herbicidas eficazes no controle dessas plantas daninhas dificilmente apresentam atividade residual suficiente para o controle até o período de 180 dias (Rodrigues \& Almeida, 2005).

Baseado nestes preceitos, o trabalho teve como objetivo verificar a eficiência de herbicidas aplicados em pré-emergência na cultura da cana-de-açúcar, na ausência ou presença de palha sobre o solo, para o controle de plantas daninhas convulvuláceas.

Foi conduzido um experimento no ano de 2007, em área anexa a Biologia Aplicada a 
Agropecuária, pertencente à Faculdade de Ciências Agrárias e Veterinárias (FCAV/UNESP), no município de JaboticabalSP. Foram utilizadas como unidades experimentais caixas plásticas com dimensões de 15 x $15 \mathrm{~cm}\left(0,0225 \mathrm{~m}^{2}\right)$ e capacidade para dois litros de solo, previamente preenchidas com LATOSSOLO VERMELHO-Escuro, areia de rio e esterco na proporção de $3: 1: 1 / 2$ (v/v/v). Cada unidade experimental continha uma espécie de corda-de-viola, utilizando quantidades de sementes necessárias para que se obtivessem 25 plantas por caixa, as quais foram semeadas superficialmente no solo.

Os tratamentos foram constituídos por um esquema fatorial com seis espécies (Ipomoea grandifolia - IPOGR, I. hederifolia IPOHF, I. nil - IPONI, I. purpurea - IPOPE, I. quamoclit - IPOQU e Merremia cissoides MRRCI) submetidas à aplicação dos herbicidas imazapic (245 g i.a. ha ${ }^{-1}$ ), diuron + hexazinona $\left(1770+330\right.$ g i.a. ha $\left.{ }^{-1}\right)$ e clomazone + hexazinona $\left(720+180 \mathrm{~g}\right.$ i.a. ha $\left.{ }^{-1}\right)$, além da testemunha sem aplicação; na presença e ausência de palha de cana-de-açúcar $\left(12 \mathrm{t} \mathrm{ha}^{-1}\right)$. $\mathrm{O}$ delineamento experimental adotado foi o inteiramente casualizado, com três repetições.

Os herbicidas foram aplicados em préemergência das plantas daninhas, utilizando um pulverizador costal à pressão constante $\left(\mathrm{CO}_{2}\right.$ comprimido) de $28 \mathrm{Lb} \mathrm{pol}^{2}$, munido de barra com quatro pontas de jato plano ("leque") AXI-110.02, espaçados de 0,5 m, com consumo de calda equivalente a $200 \mathrm{~L} \mathrm{ha}^{-1}$. No momento da aplicação, a temperatura do ar era de $31,4{ }^{\circ} \mathrm{C}$; a temperatura do solo $17,7^{\circ} \mathrm{C}$; a umidade relativa do ar $43 \%$ e a velocidade do vento $3 \mathrm{~km} \mathrm{~h}^{-1}$.
As avaliações visuais de controle foram realizadas aos 21 e 42 dias após a aplicação (DAA) dos herbicidas, atribuindo-se notas de 0 a $100 \%$, onde $0 \%$ correspondeu a nenhum controle e $100 \%$ ao controle total da espécie avaliada. Os valores foram transformados para $\operatorname{arcsen} \sqrt{x}$.

Os dados obtidos nas diferentes avaliações foram submetidos à análise de variância pelo teste $\mathrm{F}$, e, para comparação das médias utilizou-se o teste de Tukey a 5\% de probabilidade.

A porcentagem de controle geral de todas as espécies estudadas apresentou pouca oscilação durante todo o intervalo de avaliação. Na primeira avaliação, realizada aos 21 DAA, o controle variou entre 58 e $63 \%$. Por outro lado, aos 42 DAA houve ligeiro incremento no controle, que chegou a casa dos 71 e $73 \%$. Já entre os herbicidas, as misturas diuron + hexazinone e clomazone + hexazinone apresentaram controle superior a $97 \%$ em ambas as avaliações.

Em geral, a presença de palha beneficiou o efeito de controle das plantas daninhas pelos herbicidas, promovendo incrementos de $17,7 \%$ e $8,24 \%$ aos 21 e 42 DAA, respectivamente.

$\mathrm{Na}$ presença de palha, o herbicida imazapic promoveu a menor porcentagem de controle quando comparado aos demais, não ultrapassando $52,5 \%$ aos 21 DAA (Tabela 1). Entretanto, estudos indicam que a presença de palha sobre o solo reduz a lixiviação de imazapic pela chuva, aumentando o controle das plantas daninhas da área (Negrisoli et al., 2007). 
Tabela 1. Porcentagem de controle geral das espécies aos 21 e 42 dias após a aplicação (DAA) pelos diferentes herbicidas testados. Jaboticabal, 2011.

\begin{tabular}{|c|c|c|}
\hline & $21 \mathrm{DAA}$ & 42 DAA \\
\hline \multicolumn{3}{|c|}{ Espécies } \\
\hline IPOGR & $60,75 \mathrm{AB}$ & $72,87 \mathrm{~A}$ \\
\hline IPOHF & $58,41 \quad$ B & $71,17 \mathrm{~A}$ \\
\hline IPONI & $58,25 \quad \mathrm{~B}$ & $71,00 \mathrm{~A}$ \\
\hline IPOPE & $60,87 \mathrm{AB}$ & $73,08 \mathrm{~A}$ \\
\hline IPOQU & $63,79 \mathrm{~A}$ & $72,12 \mathrm{~A}$ \\
\hline MRRCI & $60,25 \mathrm{AB}$ & $72,95 \mathrm{~A}$ \\
\hline \multicolumn{3}{|c|}{ Herbicidas } \\
\hline Testemunha & $0,00 \mathrm{C}$ & $0,00 \mathrm{C}$ \\
\hline Imazapic & $38,33 \mathrm{~B}$ & $85,13 \mathrm{~B}$ \\
\hline Diuron + hexazinona & $98,90 \mathrm{~A}$ & $99,13 \mathrm{~A}$ \\
\hline Clomazone + hexazinona & $97,33 \mathrm{~A}$ & $97,44 \mathrm{~A}$ \\
\hline \multicolumn{3}{|c|}{ Palha } \\
\hline Ausência de palha & $54,54 \mathrm{~B}$ & $69,09 \mathrm{~B}$ \\
\hline Presença de palha & $66,33 \mathrm{~A}$ & $75,30 \mathrm{~A}$ \\
\hline F esp. & $4,80 * *$ & $1,20 \mathrm{NS}$ \\
\hline F herb. & $3626,89 * *$ & $4022,41 * *$ \\
\hline F palha & $241,22 * *$ & $80,60 * *$ \\
\hline F esp. $x$ herb. & $5,13 * *$ & $1,65 \mathrm{NS}$ \\
\hline F esp. $x$ palha & $2,06 * *$ & $0,33 \mathrm{NS}$ \\
\hline F herb. x palha & $68,45 * *$ & $0,69 * *$ \\
\hline F esp. $x$ herb. $x$ palha & $4,04 * *$ & $0,95 \mathrm{NS}$ \\
\hline $\mathrm{CV}(\%)$ & 7,48 & 5,7 \\
\hline
\end{tabular}

Médias seguidas da mesma letra não diferem entre si ao nível de 5\% de probabilidade pelo teste de Tukey; * significativo ao nível de 5\% de probabilidade pelo teste de Tukey; ** Significativo ao nível de $1 \%$ de probabilidade pelo teste de Tukey.

Isolando os fatores, observa-se que os herbicidas diuron + hexazinona e clomazone + hexazinona apresentaram comportamentos semelhantes, com controle superior a $97 \%$ para todas as espécies de corda-de-viola (Tabela 2).

Avaliando o comportamento dos herbicidas clomazone + hexazinona em cana de açúcar, Azania et al. (2009a) obsevaram que o controle de plantas daninhas das famílias Convolvulaceae e Euphorbiaceae foi afetado pela presença de palha. Contudo, a adição de trifloxysulfuron-sodium + ametrina proporcionou incremento no controle de $I$. grandifolia em canavial na presença de palhada (Monquero et al., 2009b). Estudo realizado por Maciel et al. (2008) mostrou que a mistura diuron + hexazinona no controle de Brachiaria decumbens na presença de palha de cana-deaçúcar, foi eficiente, alcançando 91,2\%, fato esse ocorrido até o fechamento da cultura. 
Tabela 2. Porcentagem de controle das plantas daninhas pelos diferentes herbicidas, na presença de palha, aos 21 DAA. Jaboticabal, 2011.

\begin{tabular}{ccccc}
\hline Espécies & \multicolumn{3}{c}{ Herbicidas } \\
\hline & Testemunha & Imazapic & Diuron + hexazinona & Clomazone + hexazinona \\
\hline IPOGR & $7,50 \mathrm{Cc}$ & $38,33 \mathrm{Bb}$ & $99,66 \mathrm{Aa}$ & $97,50 \mathrm{Aa}$ \\
IPOHF & $7,50 \mathrm{Cc}$ & $34,16 \mathrm{Bbc}$ & $97,66 \mathrm{Aa}$ & $94,33 \mathrm{Aa}$ \\
IPONI & $6,66 \mathrm{Cc}$ & $28,33 \mathrm{Bc}$ & $98,00 \mathrm{Aa}$ & $100,00 \mathrm{Aa}$ \\
IPOPE & $9,16 \mathrm{Cc}$ & $37,50 \mathrm{Bb}$ & $98,00 \mathrm{Aa}$ & $98,33 \mathrm{Aa}$ \\
IPOQU & $5,83 \mathrm{Cc}$ & $52,50 \mathrm{Bab}$ & $99,16 \mathrm{Aa}$ & $97,66 \mathrm{Aa}$ \\
MRRCI & $5,83 \mathrm{Cc}$ & $39,16 \mathrm{Bb}$ & $97,66 \mathrm{Aa}$ & $98,33 \mathrm{Aa}$ \\
\hline
\end{tabular}

Médias seguidas da mesma letra, não diferem entre si pelo teste de Tukey, sendo que letras maiúsculas comparam os efeitos das espécies dentro de cada herbicida (horizontal) e minúsculas comparam os efeitos dos herbicidas dentro de cada espécie (vertical).

Ao se comparar o efeito dos herbicidas na presença e na ausência de palha, o herbicida imazapic proporcionou as menores porcentagens de controle aos 21 DAA, sendo inferior a 25 e $53 \%$, respectivamente (Tabela 3). Já aos 42 DAA, houve um grande incremento no tratamento com imazapic, superando $80 \%$ de eficiência, tanto na ausência quanto na presença de palha.
Os herbicidas diuron + hexazinona e clomazone + hexazinona apresentaram maiores porcentagens de controle das plantas daninhas, independente da presença ou ausência de palha no local (Tabela 3). Nas duas situações, o controle foi ligeiramente incrementado na presença de palha, alcançando $100 \%$ para combinação diuron + hexazinona.

Tabela 3. Porcentagem de controle das espécies pelos herbicidas, na presença ou ausência de palha, aos 21 e 42 DAA. Jaboticabal, 2011.

\begin{tabular}{crrrr}
\hline \multirow{2}{*}{ Tratamentos } & \multicolumn{2}{c}{$21 \mathrm{DAA}$} & \multicolumn{2}{c}{$42 \mathrm{DAA}$} \\
\cline { 2 - 5 } & ausência & presença & ausência & \multicolumn{1}{c}{ presença } \\
\hline Testemunha & $0,00 \mathrm{Bc}$ & $14,16 \mathrm{Ac}$ & $0,00 \mathrm{Bc}$ & $14,16 \mathrm{Ac}$ \\
Imazapic & $24,16 \mathrm{Bb}$ & $52,50 \mathrm{Ab}$ & $81,11 \mathrm{Bb}$ & $89,16 \mathrm{Ab}$ \\
Diuron + hexazinona & $97,61 \mathrm{Aa}$ & $100,00 \mathrm{Aa}$ & $98,27 \mathrm{Aa}$ & $100,00 \mathrm{Aa}$ \\
Clomazone + hexazinona & $96,93 \mathrm{Aa}$ & $98,27 \mathrm{Aa}$ & $97,00 \mathrm{Aa}$ & $97,88 \mathrm{Aa}$ \\
\hline
\end{tabular}

Médias seguidas da mesma letra, não diferem entre si pelo teste de Tukey, sendo que letras maiúsculas comparam os efeitos da presença ou ausência de palha dentro de cada herbicida (horizontal) e minúsculas comparam os efeitos dos herbicidas dentro de presença ou ausência de palha (vertical).

Segundo Azania et al. (2003), algumas espécies de plantas daninhas predominantes em cana-de-açúcar apresentaram comportamento diferenciado em função da quantidade de palha depositada sobre o solo. Monquero et al. (2009b) utilizando quantidades entre 15 e $20 \mathrm{t}$ ha $^{-1}$ de palha, mesmo sem a aplicação de herbicidas, foi observada redução significativa 
na emergência de I. grandifolia. O mesmo ocorreu em áreas de plantio direto, onde a presença da palha de cana-de-açúcar reduziu a emergência das plantas infestantes mesmo sem a aplicação de herbicidas (Maciel et al., 2008). Entretanto, resultados de Gravena et al. (2004) revelam que apesar da palha ter reduzido as populações de Senna obtusifolia, I. hederifolia, I. grandifolia e I. nil, os níveis de controle foram insatisfatórios.

As combinações diuron + hexazinona $\left(1770+330 \mathrm{~g} \mathrm{ha}^{-1}\right)$ e clomazone + hexazinona $\left(720+180 \mathrm{~g} \mathrm{ha}^{-1}\right)$, aplicadas na presença e na ausência de palhada de cana-de-açúcar foram efetivas no controle das espécies Ipomoea grandifolia, Ipomoea hederifolia, Ipomoea nil, Ipomoea purpurea, Ipomoea quamoclit e Merremia cissoides. Contudo, o controle foi ligeiramente incrementado na presença de $12 \mathrm{t}$ ha $^{-1}$ de palha.

\section{Referências}

AZANIA, A.A.P.M. et al. Interferência da palha de cana-de-açúcar (Saccharum spp.) na emergência de espécies de plantas daninhas da família convolvulaceae. Planta Daninha, v.20, n.2, p.239-243, 2003.

AZANIA, C.A.M. et al. Manejo químico de convolvulaceae e euphorbiaceae em cana-deaçúcar em período de estiagem. Planta Daninha, v.27, n.4, p.841-848, 2009a.

AZANIA, A.A.P.M. et al. Superação da dormência de sementes de corda-de-viola (Ipomoea quamoclit e I. hederifolia). Planta Daninha, v.27, n.1, p.23-27, 2009b.

CHRISTOFFOLETI, P.J. et al. Conservation of natural resources in Brazilian agriculture: Implications on weed biology and management. Crop Protection, v.26, n.1 p.383-389, 2007.

CONAB: Companhia Nacional de Abastecimento. Acompanhamento da safra brasileira - safra 2010/2011. Disponível em: <http://www.conab.gov.br > Acesso em: 09 ago. de 2011.

CORREIA, N.M.; DURIGAN, J.C. Emergência de plantas daninhas em solo coberto com palha de cana-de-açúcar. Planta Daninha, v.22, n.1, p.11-18, 2004.

GRAVENA, R. et al. Controle de plantas daninhas através da palha de cana-de-açúcar associada à mistura dos herbicidas trifloxysulfuron sodium + ametrina. Planta Daninha, v.22, n.3, p.419-427, 2004.

KISSMANN, K.G.; GROTH, D. Convolvulaceae Juss. In: KISSMANN, K.G.; GROTH, D. Plantas infestantes e nocivas. 2.ed. São Paulo: BASF Brasileira, 1999. p. 673-693.

KUVA, M.A. et al. Períodos de interferência das plantas daninhas na cultura da cana-deaçucar. III-capim brachiaria (Brachiaria decumbens) e capim colonião (Panicum maximum). Planta Daninha, v.21, n.1, p.3744, 2003.

KUVA, M.A. et al. Padrões de infestação de comunidades de plantas daninhas no agroecossistema de cana-crua. Planta Daninha, v.26, n.3, p.549-557, 2008.

MACIEL, C.D.G. et al. Eficiência e seletividade dos herbicidas trifloxysulfuronsodium + ametryne e hexazinone + diuron em função da tecnologia de aplicação e do manejo mecânico da palha de cana-de-açúcar na linha de plantio. Planta daninha, v.26, n.3, p.665676, 2008.

MONQUERO, P.A. et al. Eficácia de herbicidas aplicados em diferentes épocas e espécies daninhas em área de cana-de-açúcar colhida. Planta Daninha, v.27, n.2, p.309-317, 2009a.

MONQUERO, P.A. et al. Eficácia de herbicidas em diferentes quantidades de palha de cana-de-açúcar no controle de ipomoea 
grandifolia. Bragantia, v.68, n.2, p.367-372, 2009b.

NEGRISOLI, E. et al. Controle de plantas daninhas pelo amicarbazone aplicado na presença de palha de cana-de-açúcar. Planta Daninha, v.25, n.3, p.603-611, 2007.
RODRIGUES, B.N.; ALMEIDA, F.S. Guia de herbicidas. 5.ed. Londrina: Edição dos Autores, 2005. $592 \mathrm{p}$.

SILVA, I.A.B. et al . Interferência de uma comunidade de plantas daninhas com predominância de Ipomoea hederifolia na cana-soca. Planta Daninha, v.27, n.2, p.265272, 2009. 